\title{
Article \\ Genotype by Environment Interaction Analysis of Agronomic Spring Barley Traits in Iceland Using AMMI, Factorial Regression Model and Linear Mixed Model
}

\author{
Hrannar Smári Hilmarsson $1, *\left(\mathbb{D}\right.$, Simon Rio ${ }^{2, *}$ and Julio Isidro y Sánchez ${ }^{2}(\mathbb{C}$ \\ 1 Faculty of Agricultural Sciences, Agricultural University of Iceland, Hvanneyri, 311 Borgarbyggð, Iceland \\ 2 Centro de Biotecnología y Genómica de Plantas (CBGP, UPM-INIA), Universidad Politécnica de \\ Madrid (UPM) - Instituto Nacional de Investigación y Tecnología Agraria y Alimentaria (INIA), \\ Campus de Montegancedo-UPM, 28223 Pozuelo de Alarcón, Spain; j.isidro@upm.es \\ * Correspondence: hrannar@lbhi.is (H.S.H.); rio.simon@gmail.com (S.R.); Tel.: +354-843-5385 (H.S.H.)
}

check for updates

Citation: Hilmarsson, H.S.; Rio, S.; Sánchez, J.I.y Genotype by Environment Interaction Analysis of Agronomic Spring Barley Traits in Iceland Using AMMI, Factorial Regression Model and Linear Mixed Model. Agronomy 2021, 11, 499. https://doi.org/10.3390/ agronomy11030499

Received: 5 February 2021

Accepted: 3 March 2021

Published: 7 March 2021

Publisher's Note: MDPI stays neutral with regard to jurisdictional claims in published maps and institutional affiliations.

Copyright: (c) 2021 by the authors. Licensee MDPI, Basel, Switzerland. This article is an open access article distributed under the terms and conditions of the Creative Commons Attribution (CC BY) license (https:// creativecommons.org/licenses/by/ $4.0 /)$.

\begin{abstract}
Spring barley (Hordeum vulgare L.) is the most important cereal in Iceland and its national breeding program aims to select barley genotypes adapted to its environment. A critical step to understand the adaptation of Nordic barley material to a cool maritime climate is to assess the genotype by environment interaction (GxE). In this study, we evaluated the yield and thousandkernel weight (TKW) of 32 spring barley genotypes in seven Icelandic environments. We applied three methods to analyze GxE: the additive main effects and multiplicative interaction model, a factorial model, and a linear mixed model. For yield, GxE was mainly caused by a better response of six-row genotypes compared to two-row genotypes in high fertility soils. For TKW, GxE showed a pattern along a gradient of daily mean temperatures. This pattern translated into a divergent TKW response between the 2-row and 6-row genotypes, with substantial crossovers along the temperature gradient. This GxE pattern was disentangled using all three methods, illustrating the value of cross-analysis. As yield is the main trait of interest for barley cultivation in Iceland, and few crossovers of genotype performance have been observed between environments, the definition of one mega-environment was recommended for Icelandic cultivation and breeding. We identified promising genetic material for both traits and highlighted the superiority of six-row genotypes for yield.
\end{abstract}

Keywords: barley; genotype-by-environment; breeding; yield; thousand kernel weight; cross-validation

\section{Introduction}

Barley (Hordeum vulgare L.) is the fourth most cultivated cereal crop in the world after maize, wheat, and rice [1]. It is well adapted to a broad range of climatic and day-length conditions due to its large diversity [2]. Barley is by far the most important cereal crop in Iceland, despite its location on the northern margin of barley cultivation $\left(63^{\circ}-65^{\circ} \mathrm{N}\right.$ latitude). Iceland is a subarctic agricultural region characterized by a cool maritime growing season, long photoperiod, risk of frost in spring and autumn, and strong winds. Barley cultivation in Iceland consists of both 2-row (2r) and 6-row (6r) spring varieties, and most of the crop is used as animal feed, while less than $1 \%$ is for human consumption [3]. In the last lustrum, the average barley yield in Iceland was $3.142 \mathrm{t} \mathrm{ha}^{-1}$ with an average production of 5560 tons per year [1], indicating that there is still room for increasing grain yield and production when compared with other northern countries such as Norway or Finland [4,5].

The economic viability of barley cultivation in Iceland depends mostly on yield, although grain quality traits are also important [6]. Thousand-kernel weight (TKW) is a highly heritable trait and is correlated with high starch content [7], which is desirable for malting and feed. Bragason [8] proposed that the most important breeding traits for Iceland included earliness and lodging resistance to improve stability. The response of selection for those traits has been positive. For example, in the last 30 years of breeding 
trials in Iceland, there has been a reduction in days to heading, and only one trial with total yield loss due to extreme winds [9].

The Icelandic barley-breeding program has led to the release of four cultivars. The cultivars Skegla (2r released in 2002), IsLomur (6r released 2008), and IsSkumur (6r released 2008) were characterized by a short and strong straw but could not compete with the grain yields of modern 6r varieties from other Scandinavian countries. Conversely, Iskria (2r) was released in 2004 and remains one of the most popular cultivars grown in Iceland today [9].

Nurminiemi et al. [6] suggested that the most effective breeding strategy for barley in Iceland would be a specific selection for its marginal environment. Icelandic farmers face challenging abiotic conditions during the barley growing season: average temperatures around $10{ }^{\circ} \mathrm{C}$, variable rainfall ranging from 130 to $700 \mathrm{~mm}$, and a wide variety of soil textures ranging from gravely former glacier riverbeds to peaty soils with high organic matter [10].

The heterogeneity of environmental features observed within Iceland begs the question of whether there is a significant directional genotype-by-environment interaction (GxE). This interaction exists whenever the relative performance of individuals depends on the environment in which they are observed (see [11] for a review). There are two main steps to study GxE: (i) the evaluation of genotypes in multi-environment trials, that represent the diversity of environments existing in the cultivation areas; and (ii) data analysis to interpret the structure of GxE and identify the driving environmental factors, which leads to predict the performance of genotypes in new environments. Therefore, it is key to group environments with similar GxE features into mega-environments to identify germplasm with local adaptations to contrasting environmental conditions, rather than a selection based on the mean performance of widely adapted genotypes [12,13]. There are a few popular statistical methods for analyzing GxE: (i) the regression model proposed by Finlay and Wilkinson [14], in which the performance of each genotype is regressed on the environment means; (ii) the additive main effect and multiplicative interaction (AMMI) model $[15,16]$ which uses a singular value decomposition of the fitted GxE matrix to resume its variability into principal components; (iii) the genotype main effect and GxE (GGE) model proposed by Yan et al. [17] that applies the same decomposition to the sum between the main genotype effect and the GxE; (iv) the factorial regression directly models environmental covariables measured in the field [18,19]; and (v) the random modeling of an environment-specific genotype effect using the linear mixed model (LMM) [20,21].

The AMMI model has been used to assign mega-environments with the use of genotype winners according to a relevant AMMI model [12,13]. This practice has been used to assign mega-environments for wheat in Poland [22]. After selecting the most relevant AMMI model (e.g., the one that explains most of the GxE), first-rank genotypes are used to delineate mega-environments, called the winner-method [13]. Factorial regression models have been used to describe the crop yield of wheat genotype reaction to environmental covariables [23] and more recently linear mixed models have shown high predictive accuracy in cross-validation for GxE analysis [24].

Most of the GxE research on barley has been conducted in arid regions of the world [25-29] and less in maritime climates like in Iceland. Trials carried out in Scandinavia during the period 1987-1989, including Iceland, showed significant GxE across the Nordic region [6,30], and supported the use of AMMI for the analysis of GxE. This method has also been used to identify stable and high-yielding genotypes in barley trials [31,32]. International barley yield trials across the globe showed that temperature and precipitation influenced yield [33]. Temperature has also proven to be an important factor in the grain filling of barley in the Mediterranean region [29]. The impact of soil fertility as a factor driving the GxE of barley agronomic traits has not been extensively studied. However, reports have been published about crossover-type GxE (i.e., different genotype ranks depending on the environment) for soil salinity [34] and acidity [35]. Soil type has been shown to cause variability in the yield and kernel weight of spring 
barley in Iceland, where many barley genotypes were found to be unstable and seemed to perform better in one soil type than the other [36].

The evaluation of GxE has not been carried out in Iceland for spring barley. Until now, the Icelandic barley breeding program has not aimed to select specific adaptations to the various growing regions in Iceland and no formal mega-environment analysis has been conducted. In this study, we focused on the analysis of GxE for the yield and TKW of spring barley. Therefore, the aim of this study was (i) to demonstrate the value of combining several methods for analyzing and interpreting GxE, including AMMI, factorial regression model (FM), and LMM (ii) to characterize the GxE direction and magnitude caused by the environmental factors underlying GxE for both traits of $2 \mathrm{r}$ and $6 \mathrm{r}$ barley and (iii) to evaluate the existence of mega-environments in the context of Icelandic barley cultivation.

\section{Materials and Methods}

\subsection{Plant Material}

The data we used was from recommendation trials that captured the diversity between Icelandic locations (E) for barley cultivation using 32 representative genotypes $(G)$ to study the interaction of genotypes and environments (GxE) within the same year. In 2017, sixteen spring barley (Hordeum vulgare L.) cultivars (5 Finnish, 4 Swedish, 5 Norwegian, and 2 Icelandic) and 16 breeding lines (12 Icelandic, 3 Swedish, and 1 Norwegian) (Table S1) representing the germplasm adapted to the Nordic climate [37] were grown in seven locations across Iceland (Figure 1).

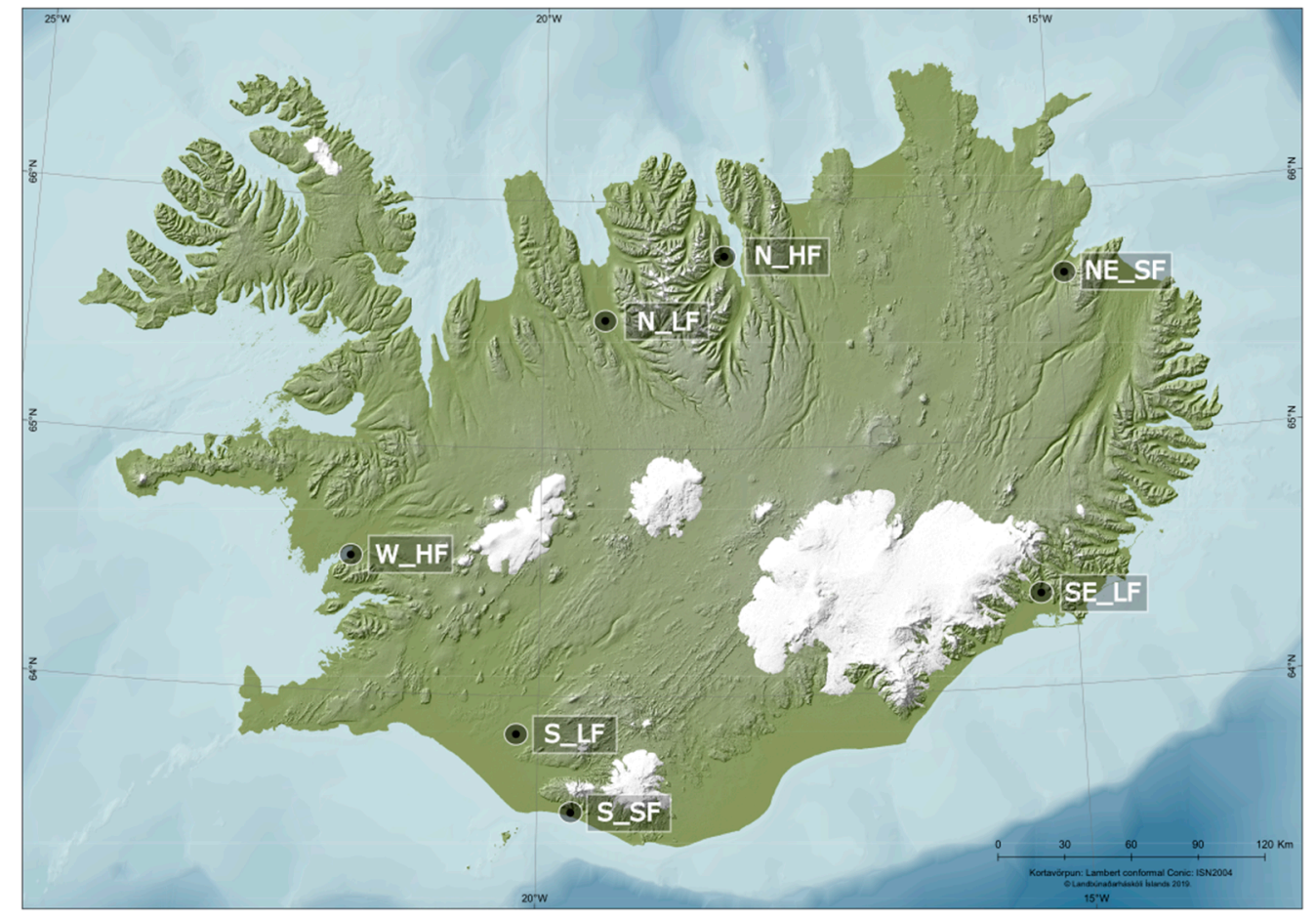

Figure 1. Locations of trails in Iceland and environmental codes. Locations are scattered across two latitude degrees and across the country in regions where barley cultivation is practiced. S: south; N: north; W: west; SE: southeast; NE: northeast; SF: semi-fertility; LF: low fertility; HF: high fertility.

\subsection{Experimental Design, Management, and Growing Conditions}

Each trial consisted of a randomized complete block design with three blocks and plots of $10 \mathrm{~m}^{2}$ (10 seed rows $8 \mathrm{~m}$ long and $1.3 \mathrm{~m}$ wide). The trials were seeded between 2017-04-26 and 2017-05-07. The trials were situated inside farmers' fields and management was conducted as a standard practice. Fertilizer application rates were decided according to soil types (Table 1), where the lowest $\mathrm{N}$ applied was $45 \mathrm{kgN} \mathrm{ha}^{-1}$ and the highest was 
$120 \mathrm{kgN} \mathrm{ha}^{-1}$ and $\mathrm{K}$ and $\mathrm{P}$ were not limiting factors. In a cold climate, $\mathrm{N}$ is set as a limiting factor to hinder tillering at the end of the growing season, which can be a problem in soils with high fertility. Plot yield was evaluated as tons of seed dry matter per hectare $\left(\mathrm{t} \mathrm{ha}^{-1}\right)$ and TKW as grams (g) per 1000 kernels, after drying the samples at $50{ }^{\circ} \mathrm{C}$ for three days and cleaning.

Table 1. Environment codes, daily mean temperatures, amount of fertilizer applied, soil texture and fertility levels. S: south; N: north; W: west; SE: southeast; NE: northeast; SF: semi-fertility; LF: low fertility; HF: high fertility.

\begin{tabular}{cccccc}
\hline Environment & Mean Temperature & \multicolumn{2}{c}{ Applied Fertilizer } & Soil Texture & Fertility Level \\
\hline & ${ }^{\circ} \mathbf{C}$ & KgN ha $^{-\mathbf{1}}$ & KgP + K ha $^{\mathbf{- 1}}$ & & \\
\hline S SF & 10.1 & 80 & $35+67$ & Sandy loam & Semi fertility \\
NE SF & 9.0 & 80 & $35+67$ & Sandy loam & Semi fertility \\
S LF & 9.7 & 120 & $52+100$ & Loamy sand & Low fertility \\
SE LF & 9.7 & 120 & $52+100$ & Gravel & Low fertility \\
W HF & 9.6 & 45 & $20+38$ & Peat & High fertility \\
N HF & 9.6 & 60 & $26+50$ & Peat & High fertility \\
N LF & 9.2 & 120 & $52+100$ & Loamy silt & Low fertility \\
\hline
\end{tabular}

Table 1 shows the environmental conditions and management of the trials across the seven environments. The environmental code for each location is the geographical location of each trial denoted by the cardinal and inter-cardinal directions and the level of soil fertility. The locations of the farms were spread around the coast of Iceland, from the $63^{\circ} 32^{\prime}$ $\mathrm{N}$ to the $65^{\circ} 46^{\prime} \mathrm{N}$. The days from sowing to harvesting were fewest at SE_LF: 136 days, and longest at W_HF: 155 days. The Icelandic meteorology office (www.vedur.is accessed on 30 January 2021) collected all climate data at weather stations that were closest to the trial locations. The data were cropped from the sowing date of each location to its harvest date (all climate data collected are listed in Table S2). The soil types at each location showed great variability in texture. Here, the soil types were categorized into three levels of fertility: low fertility (LF), semi-fertility (SF) and high fertility (HF). The soil texture that was considered least fertile, received the highest amounts of nitrogen (N) while the soil types considered most fertile received the lowest amount of $\mathrm{N}$.

\subsection{Statistical Methods}

To study GxE for yield and TKW, a set of statistical models were applied to the dataset, all derived from a base model as follows:

$$
Y_{g e r}=\mu+\alpha_{g}+\beta_{e}+(\alpha \beta)_{g e}+\omega_{e r}+E_{g e r}
$$

where $Y_{g e r}$ is the measured phenotype of genotype $g$ in the environment $e$ and block $r, \mu$ is the intercept, $\alpha_{g}$ is the main effect of genotype $g, \beta_{e}$ is the main effect of the environment $e,(\alpha \beta)_{g e}$ is the GxE effect of genotype $g$ in environment $e, \omega_{e r}$ is the effect of block $r$ in environment $e$, and $E_{g e r}$ is the error associated with genotype $g$ in environment $e$ and block $r$ with $E_{g e r} \sim N\left(0, \sigma_{E}^{2}\right)$ independent and identically distributed (IID), $\sigma_{E}^{2}$ being the error variance. This base model allows the analysis of the phenotypic variance by splitting it into parts associated with the main effect of the genotype, the main effect of the environment, their interaction (i.e., GxE), and other environmental effects including those accounted for by the experimental design. In this study, we focused on three models to study GxE: the AMMI model, the FM, and the LMM.

The AMMI model, as proposed by Gauch [15], consists in applying the singular value decomposition to the fitted GxE matrix obtained from the base model, which can be decomposed as a sum of multiplicative terms between eigenvectors and singular values. It allows most of the GxE variation to be summarized into a subset of interaction principal components (IPCs), provided that GxE interactions show patterns of (dis)similarities 
between groups of individuals and groups of environments. The AMMI method consists of the following decomposition of the GxE term of the base model in Equation (1):

$$
(\alpha \beta)_{g e}=\sum_{n=1}^{N} \lambda_{n} \gamma_{g n} \delta_{e n}
$$

where $\lambda_{n}$ is the singular value associated with IPC $n$ and correspondingly $\lambda_{n}^{2}$ is its eigenvalue, $N$ is the number of IPC components, $\gamma_{g n}$ is the eigenvector of genotype $g$ for IPC $n, \delta_{e n}$ is the eigenvector of environment $e$ for IPC $n$, with all eigenvectors scaled as unit vectors. The IPC scores were scaled as $\lambda_{n}^{0.5} \gamma_{g n}$ and $\lambda_{n}^{0.5} \delta_{e n}$, so that their products directly estimate interactions, without the need for another multiplication by $\lambda_{n}$. The family of AMMI models was further referred to as AMMIn, where " $n$ " corresponds to the number of IPC components included in the model (e.g., AMMI3 corresponds to an AMMI model with components 1 to 3 ).

Using the results from the AMMI model, the $D$ statistics of Zhang et al. [38] were calculated for each genotype and each environment as the square root of the sum of the squared eigenvector over all IPCs. This statistic was used as an indicator of the stability of genotypes and environments regarding GxE.

An FM was applied to evaluate the importance of the environmental factor driving the most GxE for each trait: soil fertility for yield and daily mean temperature for TKW. For yield, the main effect of the environment and the GxE effect of the base model in Equation (1) were decomposed by accounting directly for soil fertility as follows:

$$
\beta_{f e}=\theta_{f}+\varepsilon_{f e} \text { and }(\alpha \beta)_{g f e}=(\alpha \theta)_{g f}+(\alpha \varepsilon)_{g f e}
$$

where $\theta_{f}$ is the main effect associated with level $f$ of soil fertility with $f \in\{L F, S F, H F\}$, $\varepsilon_{f e}$ is the residual main effect of environment $e$ with the level of fertility $f,(\alpha \theta)_{g f}$ is the GxE effect of genotype $g$ for a soil with a level of fertility $f_{,}(\alpha \varepsilon)_{g f e}$ is the residual GxE effect of genotype $g$ for environment $e$ with a level of fertility $f$.

For TKW, the main effect of the environment and the GxE effect of the base model in Equation (1) were decomposed by directly accounting for daily mean temperature as follows:

$$
\beta_{e}=\eta x_{e}+\varepsilon_{e} \text { and }(\alpha \beta)_{g e}=(\alpha \eta)_{g} x_{e}+(\alpha \varepsilon)_{g e}
$$

where $\eta$ is the main regression effect of TKW on daily mean temperature, $x_{e}$ is the daily mean temperature measured in environment $e$ (as presented in Table 1 ), $\varepsilon_{e}$ is the residual main effect of environment $e,(\alpha \eta)_{g}$ is the GxE regression effect of TKW on the daily mean temperature for genotype $g,(\alpha \varepsilon)_{g e}$ is the residual GxE effect of genotype $g$ for environment $e$. The FM for TKW consists of a regression on daily mean temperature while the fertility factor used for yield includes three levels to better account for the GxE variability, which explains the differences in degrees of freedom between the two traits in the analysis of variances (AOV) tables (see below).

We applied an LMM approach to evaluate how different environments translate into specific genetic variances and how genetic values correlate between environments. The main genetic effect and the GxE effect were merged into a random variable with the following distribution:

$$
G_{g e} \sim N\left(0, \sigma_{G e}^{2}\right) \forall g, e, \operatorname{cor}\left(G_{g e}, G_{g e^{\prime}}\right)=\rho_{e e^{\prime}}, \operatorname{cor}\left(G_{g e}, G_{g^{\prime} e^{\prime}}\right)=0 \forall g \neq g^{\prime}, e, e^{\prime}
$$

where $G_{g e}$ is the random effect of genotype $g$ in environment $e, \sigma_{G e}^{2}$ is the genetic variance in environment $e, \rho_{e e^{\prime}}$ is the genetic correlation between the environments $e$ and $e^{\prime}$, and independence is assumed between $G_{g e}$ and $E_{g e r}$ for all $g, e$, and $r$.

All analyses were performed using $R$ ( $R$ Core Team). The significance of the factors of all models was evaluated using an F test. The AMMI model was implemented using the $R$ package agricolae [39]. The GxE sums of squares (SS) associated with "noise" (GxE $\left.\mathrm{N}_{\mathrm{N}} \mathrm{SS}\right)$ 
were calculated by multiplying the mean squares of the error with the degrees of freedom associated with GxE, as proposed by Gauch and Zobel [12]. The GxE SS associated with "signal" (GxES SS) was then calculated as the difference between the total GxE SS and GxE . $_{\text {. }}$ The relevant variation for identifying mega-environments was calculated as $\left(G x E_{S} S S+G\right.$ SS)/Tr SS, where G SS corresponds to the SS associated with the main effect of the genotype and $\mathrm{Tr}$ SS corresponds to the SS associated with "treatment" (i.e., the joint effect of genotype, environment, and GxE). For FMs, the figure of the expected response according to soil fertility or temperature was obtained by fitting a model including only the main effect of the genotype, the main effect of the tested environmental factor, and the effect of their interaction. Other residual GxE effects were discarded to limit the impact of standardization on such residuals. The LMM was implemented using the $R$ package lme4 [40].

\section{Results}

\subsection{Base Model Analysis of Variance}

For the base model, the AOV for yield revealed that the main effect of the genotype $(p<0.001)$ contributed the most to the variation, $34.2 \%$ of the total SS (Table 2). The main effect of the environment $(p<0.001)$ contributed $31.2 \%$, and the GxE effect $(p<0.001) 15.2 \%$, of the total SS.

Table 2. Analysis of variance for yield using the base model the additive main effect and multiplicative interaction (AMMI) model and the factorial model. With degrees of freedom (Df), sums of squares (SS), mean square (MS), the F-value, $p$-value and the proportion of SS associated with each factor over the total SS (\%SS).

\begin{tabular}{|c|c|c|c|c|c|c|c|}
\hline Model & Factors & Df & SS & MS & F-Value & $p$-Value & $\%$ SS \\
\hline \multirow{5}{*}{ Base Model } & Genotype & 31 & 429.8 & 13.87 & 25.61 & $<0.001$ & 34.2 \\
\hline & Environment & 6 & 392.9 & 65.49 & 120.98 & $<0.001$ & 31.2 \\
\hline & GxE & 186 & 190.9 & 1.03 & 1.90 & $<0.001$ & 15.2 \\
\hline & Design & 14 & 8.9 & 0.63 & 1.17 & 0.294 & 0.7 \\
\hline & Error & 434 & 234.9 & 0.54 & & & 18.7 \\
\hline \multirow{7}{*}{ AMMI Model } & GxE & 186 & 190.9 & 1.03 & 1.90 & $<0.001$ & 15.2 \\
\hline & IPC1 & 36 & 86.6 & 2.41 & 4.45 & $<0.001$ & 6.9 \\
\hline & IPC2 & 34 & 35.1 & 1.03 & 1.91 & 0.002 & 2.8 \\
\hline & IPC3 & 32 & 27.3 & 0.85 & 1.57 & 0.027 & 2.2 \\
\hline & IPC4 & 30 & 21.0 & 0.70 & 1.30 & 0.137 & 1.7 \\
\hline & IPC5 & 28 & 12.1 & 0.43 & 0.80 & 0.758 & 1.0 \\
\hline & IPC6 & 26 & 9.1 & 0.35 & 0.64 & 0.916 & 0.7 \\
\hline \multirow{6}{*}{ Factorial Model } & Environment & 6 & 392.9 & 65.49 & 120.98 & $<0.001$ & 31.2 \\
\hline & Soil fertility & 2 & 243.2 & 121.60 & 224.64 & $<0.001$ & 19.3 \\
\hline & Other Factors & 4 & 149.7 & 37.43 & 69.15 & $<0.001$ & 11.9 \\
\hline & GxE & 186 & 190.9 & 1.03 & 1.90 & $<0.001$ & 15.2 \\
\hline & GxSoil & 62 & 93.8 & 1.51 & 2.79 & $<0.001$ & 7.5 \\
\hline & GxOther Fact. & 124 & 97.1 & 0.78 & 1.46 & 0.004 & 7.7 \\
\hline
\end{tabular}

For TKW, the AOV for the base model revealed that the main effect of the genotype $(p<0.001)$ contributed the most to the variation, $42.2 \%$ of the total SS, while the main effect of the environment $(p<0.001)$ contributed $15.9 \%$, and the GxE effect $(p<0.001) 24 \%$, of the total SS (Table 3). 
Table 3. Analysis of variance for the thousand kernel weight using the base model, the AMMI model and the factorial model. With degrees of freedom (Df), sums of squares (SS), mean square (MS), the F-value, $p$-value and the proportion of SS associated with each factor over the total SS (\%SS).

\begin{tabular}{|c|c|c|c|c|c|c|c|}
\hline Model & Factors & Df & SS & MS & F-Value & $p$-Value & $\%$ SS \\
\hline \multirow{5}{*}{ Base Model } & Genotype & 31 & 3396.9 & 109.58 & 34.57 & $<0.001$ & 42.2 \\
\hline & Environment & 6 & 1279.2 & 213.21 & 44.10 & $<0.001$ & 15.9 \\
\hline & GxE & 186 & 1930.6 & 10.38 & 3.27 & $<0.001$ & 24.0 \\
\hline & Design & 14 & 67.7 & 4.84 & 1.53 & 0.098 & 0.8 \\
\hline & Error & 434 & 1375.6 & 3.17 & & & 17.1 \\
\hline \multirow{7}{*}{ AMMI Model } & GxE & 186 & 1930.6 & 10.38 & 3.27 & $<0.001$ & 24.0 \\
\hline & IPC1 & 36 & 1104.9 & 30.69 & 9.68 & $<0.001$ & 13.7 \\
\hline & IPC2 & 34 & 298.3 & 8.77 & 2.77 & $<0.001$ & 3.7 \\
\hline & IPC3 & 32 & 199.8 & 6.24 & 1.97 & 0.002 & 2.5 \\
\hline & IPC4 & 30 & 164.7 & 5.49 & 1.73 & 0.011 & 2.0 \\
\hline & IPC5 & 28 & 119.4 & 4.26 & 1.34 & 0.118 & 1.5 \\
\hline & IPC6 & 26 & 43.1 & 1.66 & 0.52 & 0.977 & 0.5 \\
\hline \multirow{6}{*}{ Factorial Model } & Environment & 6 & 1279.2 & 213.21 & 44.10 & $<0.001$ & 15.9 \\
\hline & Temperature & 1 & 38.0 & 38.04 & 12.00 & 0.997 & 0.5 \\
\hline & Other Factors & 3 & 1241.2 & 248.24 & 78.32 & $<0.001$ & 15.4 \\
\hline & GxE & 186 & 1930.6 & 10.38 & 3.27 & $<0.001$ & 24.0 \\
\hline & GxTemp & 31 & 600.0 & 19.36 & 6.11 & $<0.001$ & 7.5 \\
\hline & GxOther Fact. & 93 & 1330.5 & 8.58 & 2.71 & $<0.001$ & 16.5 \\
\hline
\end{tabular}

For both traits, the large SS associated with the main genotype effect indicated large differences between genotype means, causing most of the variations for the trait, especially for TKW. The large proportion of SS associated with the main environmental effect for both traits also indicated large differences between environmental means. The magnitude of GxE SS was less than half of the SS associated with the main genotype effect for yield, indicating that genotype-specific responses by environment contributed less to the overall variation than the main effects of the genotype and environment. For TKW, the GxE SS was $57 \%$ of the SS associated with genotype suggesting a substantial contribution of GxE to the overall genetic variation.

\subsection{Additive Main Effects and Multiplicative Interaction for Yield}

The AMMI analysis for yield showed that the first IPC accounted for $6.9 \%(p<0.001)$ of the total SS and $45.4 \%$ of the GxE SS (Table 2). The following main IPC components, IPC2 and IPC3, explained further $2.8 \%(p=0.002)$ and $2.2 \%(p=0.027)$ of the total SS, respectively. For yield, the GxES was $53 \%$ of the total GxE SS, indicating that half of the GxE variation could be used for interpretation and prediction purposes. As IPC2-6 captured small proportions of the GxE SS and mostly noise, the AMMI1 model was the most relevant. The relevant variation for identifying mega-environments, defined as the ratio of the sum of genotype and $\mathrm{GxE}_{\mathrm{S}}$ to the total treatment SS, was $51 \%$. The AMMI biplot for yield is shown in Figure 2A and summarizes the variation associated with both the mean response and the IPC1 scores of genotypes and environments. On this biplot, $89.7 \%$ of the treatment SS was captured (Table 2). Other biplots with subsequent IPCs are presented in Figure S1. 
A

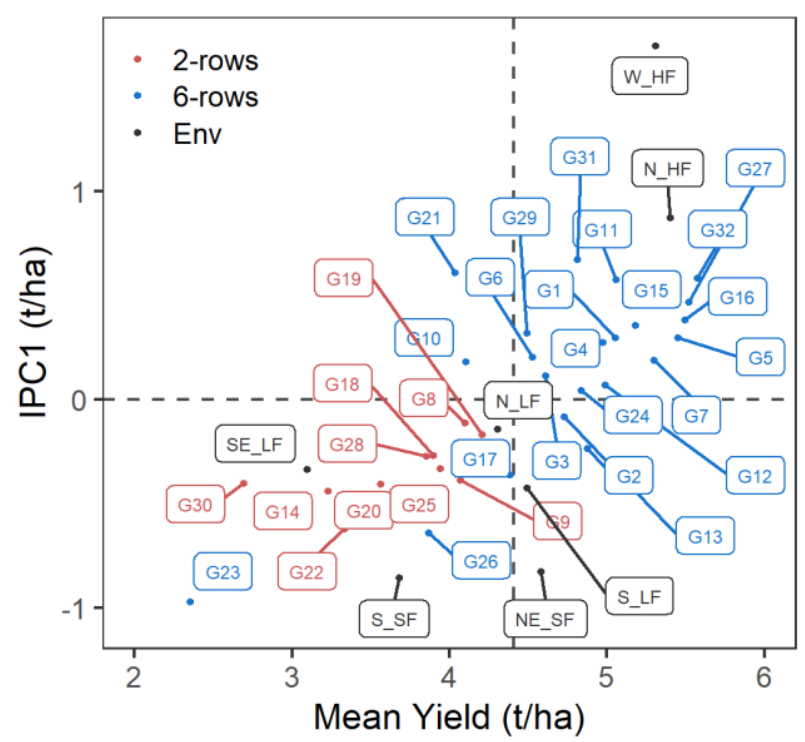

B

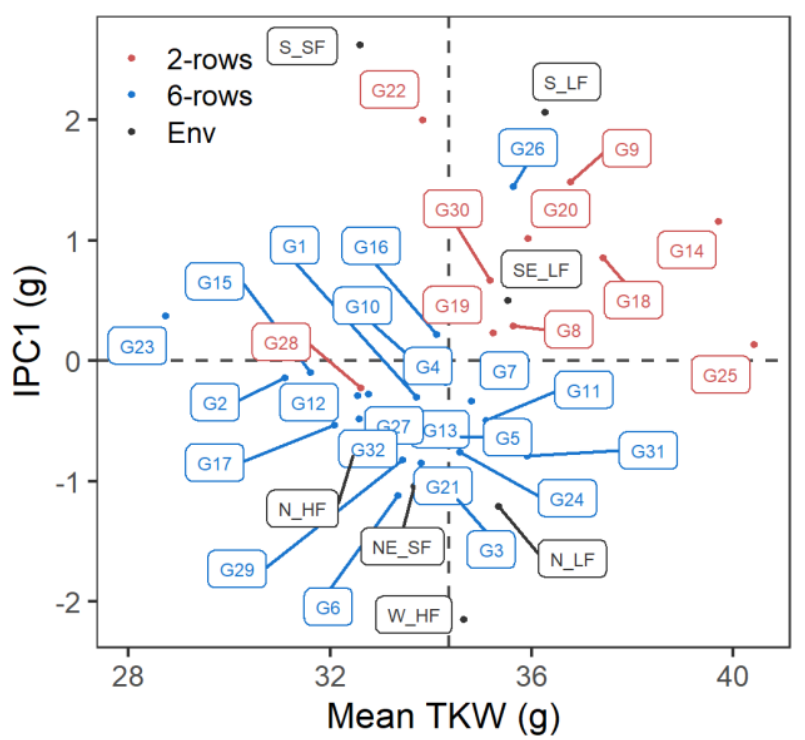

Figure 2. Biplots based on results from additive main effects and multiplicative interaction (AMMI) model with a mean response and IPC1 for (A) yield and (B) thousand-kernel weight (TKW). Environments are colored in black, and genotypes are colored according to their row type: $6 \mathrm{r}$ are in blue and $2 \mathrm{r}$ are in red. The overall mean response $\left(4.4 \mathrm{t} \mathrm{ha}^{-1}\right.$ for yield and $34.4 \mathrm{~g}$ for TKW) and the overall mean IPC1 score ( 0 for both traits) are indicated by a dashed line.

The overall mean yield was $4.4 \mathrm{tha}^{-1}$. The highest mean yields for specific environments were observed at N_HF $\left(5.4 \mathrm{t} \mathrm{ha}^{-1}\right)$ and W_HF $\left(5.3 \mathrm{t} \mathrm{ha}^{-1}\right)$. These were also the only two environments with high fertility (HF) soils. The lowest mean yield was observed at SE_LF $\left(3.1 \mathrm{tha}^{-1}\right)$. The highest yielding genotype was a Finnish cultivar: G32 $\left(6 \mathrm{r}, 5.6 \mathrm{t} \mathrm{ha}^{-1}\right)$, and the lowest yielding genotype was G23 $\left(6 \mathrm{r}, 2.4 \mathrm{tha}^{-1}\right)$. On average, $6 \mathrm{r}$ genotypes achieved a higher yield $\left(4.7 \mathrm{tha}^{-1}\right)$ compared to $2 \mathrm{r}$ genotypes $\left(3.7 \mathrm{t} \mathrm{ha}^{-1}\right)$. The highest yielding $2 \mathrm{r}$ genotype was the Icelandic cultivar G19 $\left(4.2 \mathrm{t} \mathrm{ha}^{-1}\right)$ and the lowest yielding $2 \mathrm{r}$ genotype was G30 $\left(2.7 \mathrm{tha}^{-1}\right)$.

The results from AMMI1 model on the biplot in Figure 2A showed that the IPC1 scores for environments, scaled to be in phenotypic units, ranged from -0.9 (S_SF) to 1.7 (W_HF) and the environments N_HF and W_HF were the only ones that had positive IPC1 values, with IPC1 scores of 0.9 and 1.7, respectively. Environments with low fertility, N_LF, SE_LF, and S_LF, had IPC1 values close to zero, $-0.1,-0.3$, and -0.4 , respectively. The semi-fertility environments NE_SF and S_SF had the most negative IPC1 scores of -0.8 and -0.9 , respectively. The IPC1 score for genotypes ranged from -1 (6r, G23) to 0.7 ( $6 r$, G31). The $2 r$ genotype that showed the lowest IPC1 score was G22 (-0.6) and the $2 \mathrm{r}$ genotype with the highest IPC1 score was G8 $(-0.1)$. The $6 \mathrm{r}$ and $2 \mathrm{r}$ genotypes were mostly separated on the AMMI1 biplot (Figure 2A). On average, 6r genotypes had both a higher mean yield and IPC1 score compared to $2 \mathrm{r}$ genotypes. These results indicated that $6 \mathrm{r}$ genotypes yielded particularly better than $2 \mathrm{r}$ genotypes in the high fertility environments N_HF and W_HF that had both the highest mean yield and IPC1 scores. The gap between $6 \mathrm{r}$ and $2 \mathrm{r}$ genotypes was more limited in environments with low IPC1 scores such as S_SF or NE_SF.

The ranking of genotypes based on the AMMI1 model (Table S3), declared three winners (G32, G5, and G16) and suggested the existence of three mega-environments, as proposed by Gauch (2013). The genotype G32 showed the highest yield in four environments (SE_LF, W_HF, N_HF, and N_LF). The genotype G16 showed the highest mean yield for environment S_LF. The genotype G5 had the highest yield for environments S_SF and NE_SF. However, these three genotypes were always ranking high in all environments according to AMMI1 (Table S3), and only a few crossovers could be observed between all genotypes along IPC1, as shown in Figure S2A. 


\subsection{Additive Main Effects and Multiplicative Interaction for Thousand-Kernel Weight}

The AMMI analysis for TKW showed that IPC1 accounted for 13.7\% $(p<0.001)$ of the total SS and $57 \%$ of the GxE SS (Table 3). The following main IPC components, IPC 2 and IPC3, explained further $3.7 \%(p<0.001)$ and $2.5 \%(p=0.002)$ of the total SS, respectively. For TKW, the GxE was $69 \%$ of the total GxE SS, indicating that more than two-thirds of the GxE variation was considered reliable for interpretation and prediction purposes. Since IPC1 captured most of the GxES, AMMI1 was considered as the most relevant model from the AMMI model family. For TKW, the relevant variation for identifying megaenvironments was higher than for yield (72\%). The AMMI1 model for TKW is illustrated in a biplot shown in Figure 2B and includes the mean response for TKW and the IPC1 scores, capturing $87.5 \%$ of the treatment SS (Table 3). Other biplots with subsequent IPCs are presented in Figure S3.

The overall mean TKW was 34.4g. The highest mean was observed at S_LF (36.3 g) and the lowest at N_HF (32.5 g). Environments that were classified with low fertility (S_LF, SE_LF, and N_LF) had the highest TKW mean estimates. The genotype with the highest mean TKW was a Swedish breeding line, G25 (2r, $40.4 \mathrm{~g})$. The genotype with the lowest mean TKW was G23 (6r, $28.7 \mathrm{~g})$. On average, $6 \mathrm{r}$ genotypes had a lower TKW ( $33.5 \mathrm{~g}$ ) compared to $2 \mathrm{r}$ genotypes $(36.3 \mathrm{~g}$ ). The $6 \mathrm{r}$ genotype with the highest TKW observed was the Icelandic breeding line G31 (35.9 g) and the lowest TKW mean observed for a $2 \mathrm{r}$ genotype was G28 (32.6g).

The AMMI1 biplot showed that all three environments located in the south of Iceland (S_SF, S_LF, and SE_LF) were the only environments with positive IPC1 scores (2.6, 2.1, and 0.5 ) for TKW (Figure 2B). When looking at the IPC1 score for genotypes, the results showed that the $6 \mathrm{r}$ and $2 \mathrm{r}$ genotypes were mostly separated groups (Figure 2B). The Icelandic breeding line G28 was the only $2 r$ genotype that showed a negative IPC1 value $(-0.2)$. The $6 \mathrm{r}$ genotype with the highest IPC1 score was the Icelandic breeding line G26 that scored 1.4. As for yield, the $6 \mathrm{r}$ and $2 \mathrm{r}$ genotypes were mostly separated on the AMMI1 biplot (Figure 2B). On average, 2r genotypes had both a higher mean TKW and IPC1 score compared to $6 r$ genotypes. Our results showed that $2 r$ genotypes had a positive GxE with environments in the south of Iceland while 6r genotypes showed a negative GxE with these same environments.

The ranking of genotypes based on the AMMI1 model (Table S9) declared two winners (G25 and G14) and the existence of two mega-environments. The genotype G25 showed the highest TKW for five environments (N_HF, N_LF, NE_SF, SE_LF, and W_HF), while G14 showed the highest mean TKW for environment S_LF and S_SF. These two genotypes were always ranking high (top three) in all environments according to AMMI1. However, we observed several crossovers along IPC1 between the $2 \mathrm{r}$ and 6r genotypes (Figure S4A).

\subsection{Stability Analysis}

Results from the stability analysis of genotypes and environments for both traits based on the $D$ statistics are listed in Table S15. The range of genotype $D$ values for yield ranged from 0.3 to 1.4 , with low and high values indicating stable and unstable genotypes, respectively. The genotype G19 had the lowest $D$ value and G23 had the highest $D$ value. Environment $D$ values ranged from 1.4 to 1.9. The highest value was observed for W_HF and the lowest for S_LF. The three environments with the lowest $D$ values were located in the south of Iceland. For TKW, the range of genotype $D$ values ranged from 0.4 to 2.6. The genotype G27 had the lowest $D$ value and G22 had the highest $D$ value. Environment $D$ values ranged between 2.6 and 3.2. The environment with the lowest $D$ value was NE_SF and the environment with the highest $D$ value was S_SF.

\subsection{Environmental Factors Driving $G x E$}

For yield, soil fertility was included in a FM with three levels: LF (low fertility), SF (semi-fertility), and HF (high fertility). It explained most of the variability associated with the main effect of the environment: $19.3 \%$ of the total SS and $61.9 \%$ of the environment 
SS (Table 2). Soil fertility also accounted for a large part of the variability associated with the GxE effect: $7.5 \%$ of the total SS and $49.3 \%$ of the GxE SS. On average, environments characterized with high fertility soils yielded more compared to those characterized as less fertile. The response of each genotype according to the level of fertility is presented in Figure 3A. We observed a larger variability in high fertility soils compared to low and semi-fertility. This higher variability results mostly from a differential response between $2 \mathrm{r}$ and $6 \mathrm{r}$ genotypes; $6 \mathrm{r}$ genotypes responding better to high fertility soils compared to $2 \mathrm{r}$ genotypes (i.e., a larger increase in yield response is observed for $6 r$ genotypes between $\mathrm{SF}$ and HF soils compared to the increase observed for $2 \mathrm{r}$ genotypes).

A

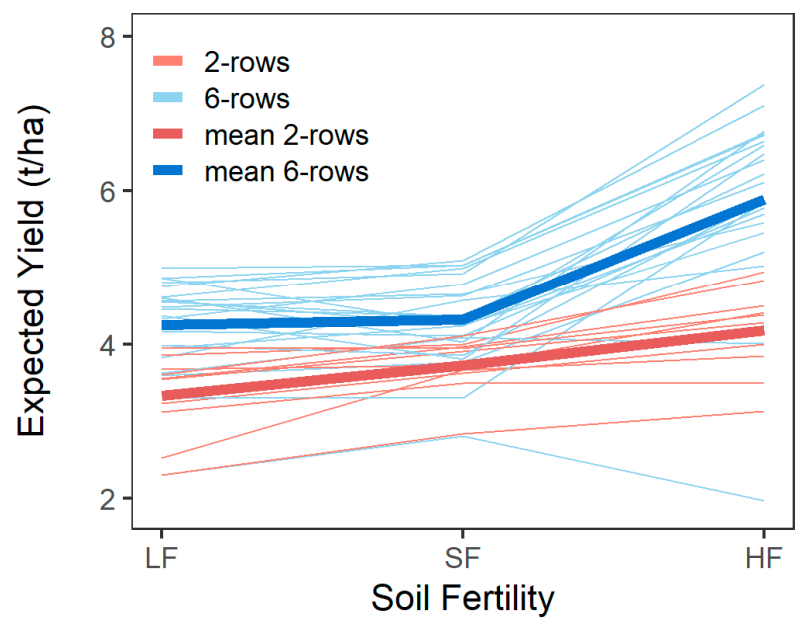

B TKW - Daily Mean Temperature

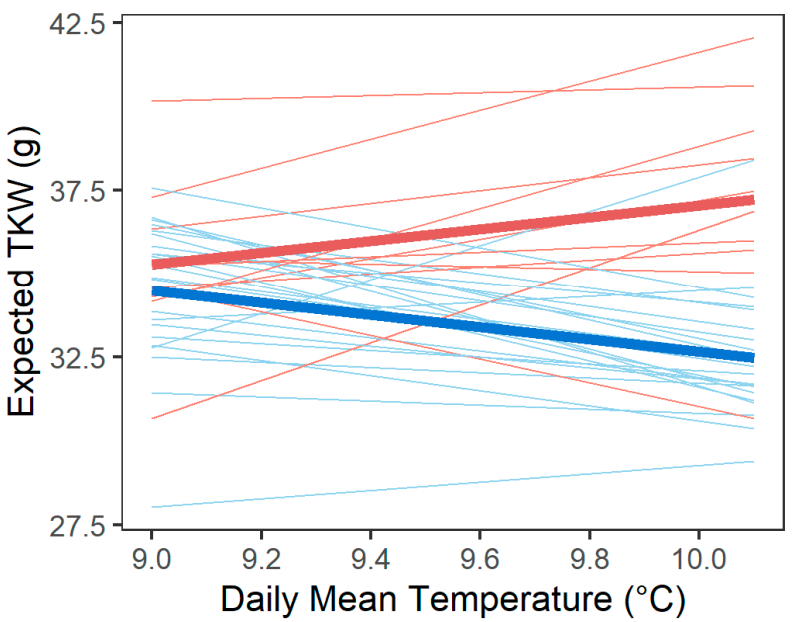

Figure 3. Expected phenotypic response of (A) yield and (B) thousand kernel weight (TKW) according to the tested environmental factor: soil fertility for yield and daily mean temperature for thousand kernel weight. Genotypes were colored according to their type: $6 \mathrm{r}$ in blue and $2 \mathrm{r}$ in red. Bolded lines represent the mean expected phenotypic response for each group.

For TKW, the daily mean temperature was included in a FM. While the daily mean temperature explained a large part of the variability associated with the GxE effect (7.5\% of the total SS and $31.2 \%$ of the GxE SS), this factor accounted for almost none of the variability associated with the main environmental effect: $0.5 \%$ of the total SS and 3.1\% of the GxE SS (Table 3). On average, environments with higher daily mean temperatures showed lower TKW. However, the $2 \mathrm{r}$ and $6 \mathrm{r}$ groups responded in a divergence pattern along the temperature gradient. The higher the mean temperature, the lower the TKW for $6 r$ genotypes, while $2 r$ genotypes responded with higher TKW at higher mean temperatures. Figure 3B shows the response of each genotype according to the daily mean temperature gradient. The genotype with the highest mean TKW (G25) was stable across the temperature gradient. However, the genotype with the second highest mean TKW (G14) had a lower TKW in environments with lower daily mean temperatures, but exhibited the highest TKW in the environments with the highest daily mean temperatures (Figure 3B).

\subsection{Genetic Variances and Genetic Correlations between Environments}

Figure 4 shows the genetic correlations between environments and genetic variance estimates from the LMM analysis. For yield, little or no pattern was observed based on genetic correlation between environments, with estimates ranging from 0.73 to 1 . The highest genetic variances estimated were found in HF environments (1.37 for N_HF and 1.90 for W_HF), while the genetic variance estimates for SF and LF environments were all below 1.0. For TKW, a clear pattern was observed according to the geography based on genetic correlation between environments. Two groups of environments can be distinguished on the heatmap: (i) environments located in the south and southeast of Iceland (S_LF, S_SF, 
and SE_LF) and (ii) all other environments (NE_SF, N_HF, N_LF, and W_HF). Within each of these clusters, high genetic correlations were estimated between environments, while low correlations were estimated between the environments of different clusters (down to 0.23 between S_LF and W_HF). Genetic variance estimates in the south and southeast cluster showed higher values (from 6.34 to 13.27) compared to the cluster of west, north, and northeast (from 4.47 to 7.75 ).

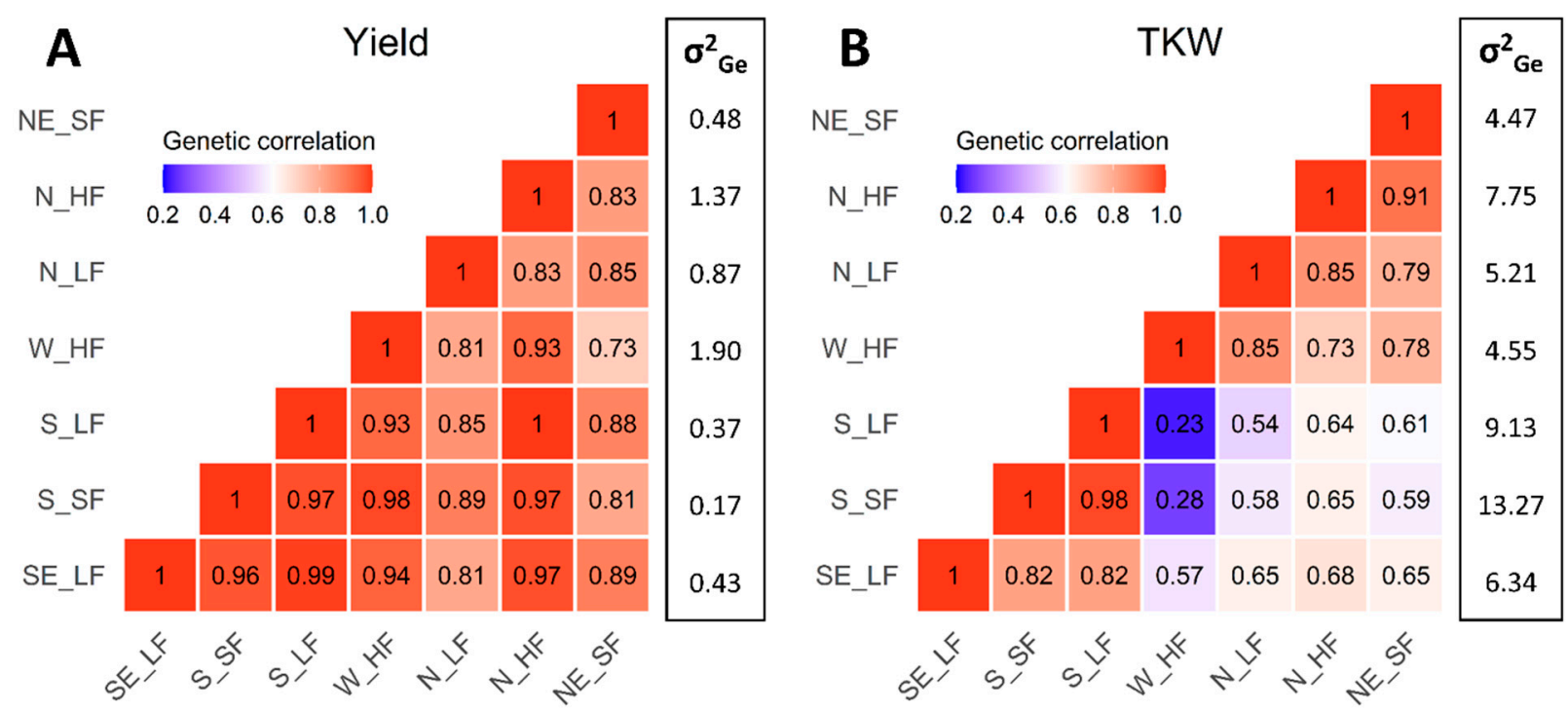

Figure 4. Heatmap of genetic correlations between environments estimated using linear mixed model for (A) yield and (B) thousand kernel weight. For each trait, the genetic variance estimates $\sigma_{G e}^{2}$ of each environment are indicated in the column at the right of the heatmap.

\section{Discussion}

\subsection{Analyzing GxE Based on a Cross-Analysis}

The strength of AMMI analysis is the possibility to simultaneously visualize genotypes and environments on biplots that facilitate the interpretation of main GxE features. On biplots, genotypes located close to environments with extreme IPC scores are likely to show a positive interaction in those environments (i.e., higher performance compared to their mean performance), and conversely for genotypes located far from those environments.

However, AMMI does not directly address the issue of identifying the environmental factors driving GxE but relies on correlation coefficients between IPC scores and environmental covariables to identify those factors [13]. To test this, we fitted a model with the environmental covariable that takes the most account of the GxE variability, which were soil fertility for yield and daily mean temperature for TKW. The response was almost identical to that observed along IPC1 using AMMI (see Figure 4B and Figure S4A), which supports daily mean temperature as being the main driver of GxE for TKW. A similar observation was made for yield and soil fertility (Figure 4A and Figure S3A).

Our results for yield showed that defining mega-environments in terms of winners as proposed by Gauch [13] could be misleading. The winner method did not categorize the seven environments into mega-environments according to clear patterns of geography, soil fertility, or climatic covariables (Table 1). The differences between winners were most often negligible and did not reflect large differences between remaining individuals, as illustrated in Figure S2A. The LMM disentangled the part of the GxE variability that involves differences in genotypes ranks (crossovers) from the GxE variability that does not (convergence/divergence). While crossovers translate into low to moderate genetic correlations between environments, convergence/divergence translates into environment-specific genetic variances along with high genetic correlations. The GxE variability observed for 
yield mostly resulted from different genetic variances between environments. Highly fertile environments tended to show higher genetic variances compared to low and semi-fertile environments. Genetic correlations for yield between environments were high (Figure 4A) and suggested the good conservation of genotype ranks between environments. On the other hand, the GxE variability observed for TKW resulted both from higher genetic variances in the south of Iceland compared to other regions, and a clear clustering between these same regions according to genetic correlations (Figure 4B). It suggested a ranking of genotypes substantially different between these clusters of regions for that trait.

\subsection{Exploiting GxE Analysis for Breeding in a Marginal Climate}

The yields observed in our experiment are comparable to the yields observed in similar trials across the globe [33] and the national averages in the Nordic region [1]. TKW, although defined as a yield component, showed less correlation with yield in the data presented here than in previous trials in Iceland [9].

Based on the FM (Figure 3) and the AMMI1 model (Figure 2), a clear distinction between $2 \mathrm{r}$ and $6 \mathrm{r}$ genotypes can be observed in terms of yield and TKW, according to their mean performance and their GxE response. Contrasting yield responses of $6 \mathrm{r}$ and $2 \mathrm{r}$ between environments have already been described in Nordic trials in 1988-1989 by Nurminiemi et al. [30], where $2 \mathrm{r}$ yielded on average more than $6 \mathrm{r}$ genotypes in Iceland (e.g., the 2r Mari released in 1960). The results suggest that breeding strategies for Northern climates have since been more focused on the $6 r$ rather than the $2 r$, or at least been more successful. The low TKW of Icelandic 2r breeding lines observed in our data (e.g., G19 and G28) may have resulted from larger breeding efforts on yield compared to grain quality.

Soil fertility showed to be the main driver of GxE for yield (Table 2) according to our FM, showing its usefulness in our investigation, as shown before in GxE analyses [23]. Higher yields of $6 \mathrm{r}$ genotypes compared to $2 \mathrm{r}$ has never been connected to soil characteristics, to the best of our knowledge. Peaty soil textures with high organic content in Iceland, like in environments W_HF and N_HF, have been reported to contain more available nitrogen [41] and a higher water capacity [42] compared to other soils. Barley has been shown to produce more ears under conditions of plentiful water [43]. Under such conditions, $6 \mathrm{r}$ shows a greater yield compared to $2 \mathrm{r}$ genotypes but led to a lower TKW in fertile soils as previously reported by Hilmarsson et al. [36]. The divergence pattern observed in Figure 3B, where the TKW of 6r genotypes decreases with increasing temperature unlike for $2 \mathrm{r}$, can be explained by the higher number of ears at higher temperatures having a greater impact on TKW for $6 r$ compared to $2 r$ genotypes. This GxE pattern may result from a complex physiological divergence between $6 \mathrm{r}$ and $2 \mathrm{r}$ genotypes, and different germplasm [44].

It is important for breeding and cultivar recommendations to select genotypes that are stable across environments. The stability of genotypes is often assessed using AMMI biplots (Figure 2) but when the first three IPCs in the AMMI analysis are significant (Tables 2 and 3), the $D$ statistics is a better estimator of genotype stability [38,45]. The results presented here do not support the reports on the decline of yield stability for barley in the Nordic region [30]. According to AMMI1 model and $D$ statistics, the most stable genotype for yield was G19, the Icelandic cultivar Iskria, which was also the highest yielding $2 \mathrm{r}$ genotype, and was stable for these two traits across soil types [36]. G24, an elite Icelandic breeding line was unstable based on $D$ statistics but not AMMI1. This suggests that relying on a single IPC is not precise enough to estimate stability, as has been previously shown [24].

In plant breeding, trial environments should represent the cultivation regions so that GxE can be accounted for when selecting the highly performing genotypes. A breeding program does not necessarily need to include a large number of environments but rather include environments in which large variance can be observed [45,46]. The LMM showed that high fertility environments had a greater genetic variance for yield, graphically supported by the FM (Figure 3) and AMMI (Figure S2A). Therefore, the fertile peaty soil texture at $\mathrm{W} \_$HF is ideal to compare genotypes for yield. The warm mean temperatures in the 
south of Iceland were associated with large genetic variances for TKW, making S_SF an ideal testing location for this trait.

The absence of major crossovers for yield did not support the definition of megaenvironments for cultivar recommendation or breeding. These results illustrate the issue of delimiting mega-environments using only the winners of a given AMMI model (three different winners for yield using AMMI1), as initially proposed by Gauch and Zobel [12]. We propose instead the use of all genotypes rather than just winners to determine megaenvironments. From a statistical point of view, we recommend the joint interpretation of AMMI results and the genetic correlation estimates obtained using the LMM. Moreover, it has been shown that LMM can outperform the AMMI model in terms of prediction accuracy (e.g., with oat yield [24]) suggesting adequate modeling of GxE using LMM. The data suggest considering Iceland as a single mega-environment for barley cultivation and breeding in Iceland. If TKW would become the main trait for breeding, there would be an opportunity to define mega-environments according to geography.

Future research should emphasize more on better characterizing GxE for these two traits by choosing relevant trial locations featuring a spectrum of soils and temperatures. Additionally, molecular markers can be used to improve the accuracy of GxE estimates and identify regions of the genome that are responsible for GxE by showing a differential effect on traits depending on the environments $[11,47]$. Such data are a great opportunity to understand further GxE in barley and the physiological pathways responsible for the interaction effect.

Supplementary Materials: The following are available online at https:/ / www.mdpi.com/2073-4 395/11/3/499/s1, Figure S1: Biplots for yield, Figure S2: Yield response, Figure S3: Biplots for TKW Figure S4: TKW response, Table S1: Genotype numbers and their names, Table S2: Climate data, Tables S3-S8: Ranking for yield of genotypes, Tables S9-S14: Ranking for TKW of genotypes, Table S15: D-statistics.

Author Contributions: Conceptualization, H.S.H. and S.R.; methodology, H.S.H. and S.R. software, S.R.; validation, S.R., H.S.H. and J.I.y.S.; formal analysis, S.R. and H.S.H.; investigation, H.S.H.; resources, H.S.H. and J.I.y.S.; data curation, H.S.H.; writing—original draft preparation, H.S.H.; writing-review and editing, H.S.H., S.R. and J.I.y.S.; visualization, S.R.; supervision, J.I.y.S.; project administration, H.S.H.; funding acquisition, H.S.H., and J.I.y.S. All authors have read and agreed to the published version of the manuscript.

Funding: This research was funded by the Icelandic agricultural productivity fund and "Erasmus+. This project has received funding from the European Union's Horizon 2020 research and innovation program under grant agreement No 818144, and also the Severo Ochoa Program for Centres of Excellence in R\&D. JIS was supported by the Beatriz Galindo Program (BEAGAL18/00115) from the Ministerio de Educación y Formación Profesional of Spain and the Severo Ochoa Program for Centres of Excellence in R\&D from the Agencia Estatal de Investigación of Spain, grant SEV-2016-0672 (2017-2021) to the CBGP.

Institutional Review Board Statement: Not applicable.

Informed Consent Statement: Not applicable.

Data Availability Statement: The data presented in this study are available upon request from the corresponding author.

Acknowledgments: Special thanks to all farmers who lent a hand and land to make these trials possible, especially Egill Gunnarsson. Acknowledgements to those who assisted and agricultural advisory center (RML) and to Simmi Brink for the assistance of generating Figure 1.

Conflicts of Interest: The authors declare no conflict of interest.

\section{References}

1. FAOSTAT_Food and Agriculture Organization of the United Nations Statistical Database. Available online: http://www.fao. org / faostat (accessed on 16 June 2020).

2. Ullrich, S.E. Barley: Production, Improvement, and Uses, 1st ed.; Wiley-Blackwell: Chichester, WS, UK, 2010; ISBN 978-0-8138-0123-0. 
3. Martin, P.; Reykdal, O.; Halland, H. Current Cereal Growing Situation in Five Northern Regions and the Potential for Using Local Cereals in Food and Drink Products; Northern Periphery and Arctic Programme: Copenhagen, Denmark, 2016.

4. Lillemo, M.; Reitan, L.; Bjørnstad, Å. Increasing Impact of Plant Breeding on Barley Yields in Central Norway from 1946 to 2008. Plant Breed. 2010, 129, 484-490. [CrossRef]

5. Öfversten, J.; Jauhiainen, L.; Kangas, A. Contribution of New Varieties to Cereal Yields in Finland between 1973 and 2003. J. Agric. Sci. 2004, 142, 281-287. [CrossRef]

6. Nurminiemi, M.; Madsen, S.; Rognli, O.; Bjornstad, A.; Ortiz, R. Analysis of the Genotype by environment Interaction of Spring Barley Tested in the Nordic Region of Europe: Relationships among Stability Statistics for Grain Yield. Euphytica 2002, 127, 123-132. [CrossRef]

7. Savin, R.; Molina-Cano, J.L. Changes in malting quality and its determinants in response to abiotic stresses. In Barley Science-Recent Advances from Molecular Biology to Agronomy of Yield and Quality; CRC Press: Boca Raton, FL, USA, 2002; pp. 523-550.

8. Bragason, Á. Sammenligning af vårbygpopulationer i Danmark og Island. Ph.D. Thesis, Veterinær-og Landbohojskole, Copenhagen, Denmark, 1985.

9. Hilmarsson, H.S.; Göransson, M.W.; Lillemo, M.; Kristjánsdóttir, P.A.; Hermannsson, J.; Hallsson, J.H. An Overview of Barley Breeding and Variety Trials in Iceland in 1987-2014. Icel. Agric. Sci. 2017, 30, 13-28. [CrossRef]

10. Arnalds, O. The Soils of Iceland; World Soils Book Series; Springer Netherlands: Dordt, The Netherlands, 2015; ISBN 978-94-0179620-0.

11. Malosetti, M.; Ribaut, J.-M.; van Eeuwijk, F.A. The Statistical Analysis of Multi-Environment Data: Modeling Genotype-byEnvironment Interaction and Its Genetic Basis. Front. Physiol. 2013, 4, 44. [CrossRef] [PubMed]

12. Gauch, H.G.; Zobel, R.W. Identifying Mega-Environments and Targeting Genotypes. Crop Sci. 1997, 37, 311-326. [CrossRef]

13. Gauch, H.G. A Simple Protocol for AMMI Analysis of Yield Trials. Crop Sci. 2013, 53, 1860-1869. [CrossRef]

14. Finlay, K.W.; Wilkinson, G.N. The Analysis of Adaptation in a Plant-Breeding Programme. Aust. J. Agric. Res. 1963, 14, 742-754. [CrossRef]

15. Gauch, H.G. Model Selection and Validation for Yield Trials with Interaction. Biometrics 1988, 44, 705-715. [CrossRef]

16. Van Eeuwijk, F.A. Linear and Bilinear Models for the Analysis of Multi-Environment Trials: I. An Inventory of Models. Euphytica 1995, 84, 1-7. [CrossRef]

17. Yan, W.; Hunt, L.A.; Sheng, Q.; Szlavnics, Z. Cultivar Evaluation and Mega-Environment Investigation Based on the GGE Biplot. Crop Sci. 2000, 40, 597-605. [CrossRef]

18. Denis, J.-B. Two Way Analysis Using Covarites. Statistics 1988, 19, 123-132. [CrossRef]

19. Van Eeuwijk, F.A.; Elgersma, A. Incorporating Environmental Information in an Analysis of Genotype by Environment Interaction for Seed Yield in Perennial Ryegrass. Heredity 1993, 70, 447-457. [CrossRef]

20. Denis, J.-B.; Piepho, H.-P.; van Eeuwijk, F.A. Modelling Expectation and Variance for Genotype by Environment Data. Heredity 1997, 79, 162-171. [CrossRef]

21. Van Eeuwijk, F.A.; Bustos-Korts, D.V.; Malosetti, M. What Should Students in Plant Breeding Know about the Statistical Aspects of Genotype $\times$ Environment Interactions? Crop Sci. 2016, 56, 2119-2140. [CrossRef]

22. Paderewski, J.; Gauch, H.G.; Mądry, W.; Gacek, E. AMMI Analysis of Four-Way Genotype $\times$ Location $\times$ Management $\times$ Year Data from a Wheat Trial in Poland. Crop Sci. 2016, 56, 2157-2164. [CrossRef]

23. Voltas, J.; López-Córcoles, H.; Borrás, G. Use of Biplot Analysis and Factorial Regression for the Investigation of Superior Genotypes in Multi-Environment Trials. Eur. J. Agron. 2005, 22, 309-324. [CrossRef]

24. Olivoto, T.; Lúcio, A.D.C.; da Silva, J.A.G.; Marchioro, V.S.; de Souza, V.Q.; Jost, E. Mean Performance and Stability in MultiEnvironment Trials I: Combining Features of AMMI and BLUP Techniques. Agron. J. 2019, 111, 2949-2960. [CrossRef]

25. Dehghani, H.; Ebadi, A.; Yousefi, A. Biplot Analysis of Genotype by Environment Interaction for Barley Yield in Iran. Agron. J. 2006, 98, 388-393. [CrossRef]

26. Kendal, E.; Tekdal, S. Application of AMMI Model for Evaluation of Spring Barley Genotypes in Multi-Environment Trials. Bangladesh J. Bot. 2016, 45, 613-620.

27. Mortazavian, S.M.M.; Nikkhah, H.R.; Hassani, F.A.; Sharif-al-Hosseini, M.; Taheri, M.; Mahlooji, M. GGE Biplot and AMMI Analysis of Yield Performance of Barley Genotypes across Different Environments in Iran. J. Agric. Sci. Technol. 2014, 16, 609-622.

28. Rodriguez, M.; Rau, D.; Papa, R.; Attene, G. Genotype by Environment Interactions in Barley (Hordeumvulgare L.): Different Responses of Landraces, Recombinant Inbred Lines and Varieties to Mediterranean Environment. Euphytica 2008, 163, $231-247$. [CrossRef]

29. Voltas, J.; van Eeuwijk, F.A.; Sombrero, A.; Lafarga, A.; Igartua, E.; Romagosa, I. Integrating Statistical and Ecophysiological Analyses of Genotype by Environment Interaction for Grain Filling of Barley I.: Individual Grain Weight. Field Crops Res. 1999, 62, 63-74. [CrossRef]

30. Nurminiemi, M.; Bjørnstad, ̊̊.; Rognli, O.A. Yield Stability and Adaptation of Nordic Barleys. Euphytica 1996, 92, 191-202. [CrossRef]

31. Verma, R.P.S.; Kharab, A.S.; Singh, J.; Kumar, V.; Sharma, I.; Verma, A. AMMI Model to Analyse GxE for Dual Purpose Barley in Multi-Environment Trials. Agric. Sci. Dig. 2016, 36, 9-16. [CrossRef]

32. Vishnu, K.; Karub, A.S.; Verma, R.P.S.; Verma, A. AMMI, GGE Biplots and Regression Analysis to Comprehend the G $\times$ E Interaction in Multi-Environment Barley Trials. Ind. J. Genet. Plant Breed. 2016, 76, 202-204. 
33. Hernandez-Segundo, E.; Capettini, F.; Trethowan, R.; van Ginkel, M.; Mejia, A.; Carballo, A.; Crossa, J.; Vargas, M.; BalbuenaMelgarejo, A. Mega-Environment Identification for Barley Based on Twenty-Seven Years of Global Grain Yield Data. Crop Sci. 2009, 49, 1705-1718. [CrossRef]

34. Isla, R.; Royo, A.; Aragüés, R. Field Screening of Barley Cultivars to Soil Salinity Using a Sprinkler and a Drip Irrigation System. Plant Soil 1997, 197, 105-117. [CrossRef]

35. Barszczak, Z.; Barszczak, T. Tolerance of wheat and barley varieties to soil acidity. Wiss. Beitrage Martin-Luther-Univ. Halle-Wittenb 1980, 20, 678-690.

36. Hilmarsson, H.S.; Göransson, M.W.; Hallsson, J.H.; Kristjánsdóttir, P.A.; Hermannsson, J. Effect of Soil Type on Barley Yields in Icelandic Cultivar Trials. Icel. Agric. Sci. 2017, 30, 73-76. [CrossRef]

37. Hilmarsson, H.S. Jarðræktarrannsóknir 2017; Rit LbhÍ nr. 102; Agricultural University of Iceland: Hvanneyri, Iceland, 2018.

38. Zhang, Z.; Cheng, L.; Zhonghuai, X. Analysis of Variety Stability Based on AMMI Model. Zuo Wu Xue Bao 1998, $24,304-309$.

39. Mendiburu, F.D. Agricolae: Statistical Procedures for Agricultural Research; R package. 2020. Available online: https://CRAN.Rproject.org $/$ package=agricolae (accessed on 2 February 2021).

40. Bates, D.; Mächler, M.; Bolker, B.; Walker, S. Fitting Linear Mixed-Effects Models Using Lme4. J. Stat. Softw. 2015, 67, 1-48. [CrossRef]

41. Pálmason, F.; Björnsson, H.; Hermannsson, J. Nýting Niturs í Kornökrum. [Nitrogen Use in Barley Fields]. In Proceedings of the Ráðunautafundur 2003, Reykjavík, Iceland, 5-7 February 2003; pp. 173-177.

42. Guðmundsson, J.; Arnalds, O.; Óskarsson, H. Vatnsheldni Mismunandi Jarðvegsflokka. [Water Holding Capacity of Different Soil Types]. In Proceedings of the Fræðaping landbúnaðarins 2006, Reykjavík, Iceland, 2-3 February 2006; pp. 362-364.

43. Jones, H.G.; Kirby, E.J.M. Effects of Manipulation of Number of Tillers and Water Supply on Grain Yield in Barley. J. Agric. Sci. 1977, 88, 391-397. [CrossRef]

44. Brantestam, A.K.; von Bothmer, R.; Dayteg, C.; Rashal, I.; Tuvesson, S.; Weibull, J. Genetic Diversity Changes and Relationships in Spring Barley (Hordeum Vulgare L.) Germplasm of Nordic and Baltic Areas as Shown by SSR Markers. Genet. Resour. Crop Evol. 2007, 54, 749-758. [CrossRef]

45. Fan, L.J.; Hu, B.M.; Shi, C.H.; Wu, J.G. A Method of Choosing Locations Based on Genotype $\times$ Environment Interaction for Regional Trials of Rice. Plant Breed. 2001, 120, 139-142. [CrossRef]

46. Lin, C.S.; Morrison, M.J. Selection of Test Locations for Regional Trials of Barley. Theor. Appl. Genet. 1992, 83, 968-972. [CrossRef]

47. Crossa, J. From Genotype $\times$ Environment Interaction to Gene $\times$ Environment Interaction. Curr. Genom. 2012, 13, 225-244. [CrossRef] 